\title{
Determinacy Through Intertemporal Capital Adjustment Costs*
}

\author{
Berthold Herrendorf \\ Universidad Carlos III de Madrid, University of Southampton, and CEPR \\ Ákos Valentinyi \\ University of Southampton, Institute of Economics of the \\ Hungarian Academy of Sciences, and CEPR
}

Current version: August 25, 2002

(First version: June 2000)

\begin{abstract}
It is well known that if there are mild sector-specific externalities, then the steady state of the standard two-sector real business cycle model can become locally indeterminate and endogenous business cycles can arise. We show that this result is not robust to the introduction of standard intertemporal capital adjustment costs, which may accrue when total capital is adjusted or when each sector's capital is adjusted. We find for both forms of adjustment costs that the steady state is determinate for all empirically plausible parameter values. We also find that determinacy occurs for a much larger range of parameter values when adjusting each sector's capital is costly.

Keywords: capital adjustment costs; determinacy; local indeterminacy; local stability; sector-specific externality.
\end{abstract}

JEL classification: E0; E3.

\footnotetext{
*An early version of this paper was entitled "Determinacy With Capital Adjustment Costs and SectorSpecific Externalities". We have profited from the comments of Jess Benhabib, Michele Boldrin, Juan Carlos Conesa, Roger Farmer, Maite Martinez-Granado, Salvador Ortigueira, Manuel Santos, András Simonovits, Juuso Välimäki, and the audiences at Carlos III, the Central Bank of Portugal, Central European University, Exeter, the Institute for International Economics Studies (Stockholm University), MadMac (Madrid Macroeconomics Seminar), the Federal Reserve Bank of Minneapolis, the SED Conference 2000, Southampton, and Warwick. Herrendorf acknowledges research funding from the Spanish Dirección General de Investigación (Grant BEC2000-0170) and from the European Union (Project 721 "New Approaches in the Study of Economic Fluctuations"). Herrendorf also thanks the SFB at Humboldt University for a productive visit in May 2002, during which this paper was completed.
} 


\section{Introduction}

For a long time, economists have debated whether business cycle fluctuations may, at least partly, be driven by self-fulfilling changes in individual beliefs. One mayor problem with this idea was that self-fulfilling changes in beliefs can occur only if the steady state is locally indeterminate (i.e. locally non-unique), whereas in the standard real business model developed by Kydland and Prescott (1982) it is determinate (i.e. locally unique). However, Benhabib and Farmer (1996) argued that determinacy is not a generic property of the model. In particular, they introduced mild sector-specific externalities into the standard two-sector version and showed that this small modification can lead to local indeterminacy. ${ }^{1}$ Since the required strength of the externalities is mild and can be defended empirically, local indeterminacy, and the implied possibility of self-fulfilling business cycles, started to look rather plausible. Numerous recent studies have therefore looked at self-fulfilling business cycles in two-sector models, such as Perli (1998), Weder (1998), Schmitt-Grohé (2000), and Harrison and Weder (2001) to name only a few.

The present paper shows that the result of Benhabib and Farmer (1996) is not generic either. In particular, we show that the local stability properties of the steady state of the two-sector real business cycle model depend critically on whether or not adjusting capital is costly. While Benhabib and Farmer assumed that it is not, we assume that it is. Our assumption can be justified by at least three arguments. First, there is substantial empirical evidence in favor of capital adjustment costs at the firm level; see Hammermesh and Pfann (1996) for a review of the evidence. Second, without capital adjustment costs Tobin's $q$ (i.e. the ratio between the price of installed capital and the price of new capital) is constant over the business cycle, which is counterfactual [Jermann (1998)]. Third, without capital adjustment costs the allocations of the two-sector model considered here have several counterfactual properties (such excess investment volatility and countercyclical consumption) that mostly disappear when capital adjustment costs are

\footnotetext{
${ }^{1}$ Boldrin and Rustichini (1994) found a related result for a growth version of the model.
} 
modeled [Huffman and Wynne (1999) and Boldrin et al. (2001)].

We consider capital adjustment costs of the standard intertemporal form introduced by Lucas and Prescott (1971) and distinguish between two possibilities: The costs can accrue either when the total capital stock is changed (irrespective of by how much each sector's capital stock changes) or when a sector's capital stock is changed (irrespective of by how much the total capital stock changes). Our main result is that both specifications eliminate the scope for local indeterminacy, and thus the scope for self-fulfilling business cycles, for all empirically plausible parameter choices. We also find that adjustment costs on sectoral capital lead to a larger (smaller) parameter range for which determinacy (local indeterminacy) occurs than adjustment costs on total capital.

The intuition for the main result of this paper is similar to that underlying the work by Wen (1998b), Guo and Lansing (2002), and Kim (2003). on the effects of capital adjustment costs on the local stability properties of the one-sector neoclassical growth model. These authors found that capital adjustment costs have an "offsetting effect": Given a strength of increasing returns that implies local indeterminacy, there is a minimum size of intertemporal capital adjustment costs that makes local indeterminacy impossible. While this offsetting effect is at work here too, the value added of our paper is to show that it matters for empirically relevant parameter values in the two-sector version of the model. This is not really an issue in the one-sector version because local indeterminacy does not occur for empirically plausible parameter values; see for example Benhabib and Farmer (1994).

The rest of the paper is organized as follows. Section 2 lays out the economic environment. Section 3 characterizes the competitive equilibrium. Section 4 reports our results. Section 5 concludes the paper. 


\section{Model Economy}

Time is continuous and runs forever. There are measures one of identical, infinitely-lived households, of identical firms that produce a perishable consumption good, and of identical firms that produce new capital goods. The representative household is endowed with the initial capital stocks, with the property rights of the representative firms, and with one unit of time at each instant. We assume that installing new capital is costly and that installed capital is sector specific. At each point in time there are then four commodities: a consumption good, a new capital good suitable for the production of consumption goods, a new capital good suitable for the production of new capital goods, and labor. Trade takes place in sequential markets.

The preferences of the representative household are represented by the following utility function:

$$
\int_{0}^{\infty} e^{-\rho t}\left(\log c_{t}-l_{c t}-l_{x t}\right) d t
$$

where $\rho>0$ is the discount rate, $\log$ is the natural logarithm, $c_{t}$ denotes the consumption good at time $t$ (which is the numeraire), and $l_{c t}$ and $l_{x t}$ are labor in the consumption- and in the capitalproducing sector. The instantaneous utility is separable in consumption and leisure, logarithmic in consumption, and linear in leisure. This functional form is standard in the literature on selffulfilling business cycles, and it would be consistent with the existence of a balanced growth path if exogenous technological progress were considered. The separability assumption does not affect the possibility of local indeterminacy [Hintermaier (2002)]. The linear utility in leisure implies an infinite labor supply elasticity, which can be justified by the lottery argument of Hansen (1985). Since it is easier to get local indeterminacy the higher is the labor supply elasticity, the determinacy results to be derived for an infinite labor supply elasticity would apply for any finite labor supply elasticity too.

The representative household's problem depends on the form that capital adjustment costs 
take. The first form arises when it is costly to change the total capital stock of the model economy, irrespective of by how much each sector's capital stock changes. In this first case the household problem, called (HP1), is to choose $c_{t}, l_{c t}, l_{x t}, x_{t}, x_{c t}, x_{x t}, k_{c t}, k_{x t}$ so as to maximize (1) subject to

$$
\left(k_{c t}+k_{x t}\right) \psi\left(\frac{x_{c t}+x_{x t}}{k_{c t}+k_{x t}}\right)=x_{t}
$$

and

$$
\begin{aligned}
& c_{t}+p_{t} x_{t}=\pi_{c t}+\pi_{x t}+w_{c t} l_{c t}+w_{x t} l_{x t}+r_{c t} k_{c t}+r_{x t} k_{x t}, \\
& \dot{k}_{c t}=x_{c t}-\delta_{c} k_{c t}, \\
& \dot{k}_{x t}=x_{x t}-\delta_{x} k_{x t}, \\
& k_{c 0}=\bar{k}_{c 0} \text { given, } \\
& k_{x 0}=\bar{k}_{x 0} \text { given, } \\
& 0 \leq c_{t}, l_{c t}, l_{x t}, x_{t}, x_{c t}, x_{x t}, k_{c t}, k_{x t}, \\
& l_{c t}+l_{x t} \leq 1 .
\end{aligned}
$$

The function $\psi: \mathbb{R}_{+} \longrightarrow \mathbb{R}_{+}$is twice continuously differentiable, monotonically increasing, and convex. The notation is as follows: $x_{t}$ is the composite new capital good produced by the capital-producing sector and $p_{t}$ is its relative price in terms of the consumption good, $\pi_{c t}$ and $\pi_{x t}$ are the two profits (which will be zero in equilibrium), $w_{c t}$ and $w_{x t}$ are the wages in the two sectors, $k_{c t}$ and $k_{x t}$ are the capital stocks in the two sectors, $r_{c t}$ and $r_{x t}$ are the corresponding real interest rates, $\delta_{c}$ and $\delta_{x}$ are the corresponding depreciation rates, and $x_{c t}$ and $x_{x t}$ are the investments in the two sectors.

The second form of capital adjustment costs arises when it matters by how much the capital stocks of each sector change, irrespective of by how much the total capital stock changes. In this second case the household's problem, called (HP2), is to choose $c_{t}, l_{c t}, l_{x t}, x_{t}, x_{c t}, x_{x t}, k_{c t}$, 
$k_{x t}$ so as to maximize (1) subject to

$$
k_{c t} \psi_{c}\left(\frac{x_{c t}}{k_{c t}}\right)+k_{x t} \psi_{x}\left(\frac{x_{x t}}{k_{x t}}\right)=x_{t}
$$

and (2b)-(2h). Again, the functions $\psi_{c}, \psi_{x}: \mathbb{R}_{+} \longrightarrow \mathbb{R}_{+}$are twice continuously differentiable, monotonically increasing, and convex.

The way in which capital adjustment costs are modeled here is in the spirit of Lucas and Prescott (1971). The strict convexity of $\psi, \psi_{c}$, and $\psi_{x}$ captures the notion that it becomes the more costly to change the capital stock the more quickly this is done. The non-negativity constraints on the two capital goods, $x_{c t}, x_{x t} \geq 0$, imply that installed capital is sector specific, which is consistent with the evidence reported by Ramey and Shapiro (2001). Nevertheless the capital stock of a sector can be reduced by not replacing depreciated capital, so in equilibrium the non-negativity constraints will not be binding close the steady state and we can ignore them from now on. It should be mentioned that the model version without capital adjustment costs is nested in our set-up for

$$
\begin{aligned}
& \psi\left(\frac{x_{c t}+x_{x t}}{k_{c t}+k_{x t}}\right)=\frac{x_{c t}+x_{x t}}{k_{c t}+k_{x t}}, \\
& \psi_{j}\left(\frac{x_{j t}}{k_{j t}}\right)=\frac{x_{j t}}{k_{j t}}, \quad j \in\{c, x\} .
\end{aligned}
$$

Note that the model version without capital adjustment costs still has sector-specific capital. This does not, however, matter for the local stability analysis because sector-specific capital alone does not have an effect [Christiano (1995) and Herrendorf and Valentinyi (2002)].

Denoting by $\lambda_{t}$ the multiplier attached to (2b) and by $\mu_{c t}$ and $\mu_{x t}$ the current value multipliers attached to the accumulation equations (2c) and (2d), the solution to (HP1) is characterized by 
(2a)-(2h) and

$$
\begin{aligned}
& c_{t}=w_{c t}=w_{x t}=\frac{1}{\lambda_{t}}, \\
& \frac{\mu_{c t}}{\mu_{x t}}=1, \\
& \frac{\mu_{c t}}{\lambda_{t} p_{t}}=\psi^{\prime}\left(\frac{x_{c t}+x_{x t}}{k_{c t}+k_{x t}}\right), \\
& \lambda_{t} r_{c t}-\mu_{c t} \delta_{c}=\lambda_{t} r_{x t}-\mu_{x t} \delta_{x}, \\
& -\dot{\mu}_{c t}+\mu_{c t} \rho=r_{c t} \lambda_{t}+\lambda_{t} p_{t}\left[\frac{x_{c t}+x_{x t}}{k_{c t}+k_{x t}} \psi^{\prime}\left(\frac{x_{c t}+x_{x t}}{k_{c t}+k_{x t}}\right)-\psi\left(\frac{x_{c t}+x_{x t}}{k_{c t}+k_{x t}}\right)\right]-\mu_{c t} \delta_{c}, \\
& \lim _{t \rightarrow \infty} \mu_{c t} k_{c t}=\lim _{t \rightarrow \infty} \mu_{x t} k_{x t}=0 .
\end{aligned}
$$

The solution to (HP2) is characterized by (2b)-(2i) and

$$
\begin{aligned}
& c_{t}=w_{c t}=w_{x t}=\frac{1}{\lambda_{t}}, \\
& \frac{\mu_{c t}}{\mu_{x t}}=\frac{\psi_{c}^{\prime}\left(\frac{x_{c t}}{k_{c t}}\right)}{\psi_{x}^{\prime}\left(\frac{x_{x t}}{k_{x t}}\right)}, \\
& \frac{\mu_{c t}}{\lambda_{t} p_{t}}=\psi_{c}^{\prime}\left(\frac{x_{c t}}{k_{c t}}\right), \\
& -\dot{\mu}_{c t}+\mu_{c t} \rho=\lambda_{t} r_{c t}+\lambda_{t} p_{t}\left[\frac{x_{c t}}{k_{c t}} \psi_{c}^{\prime}\left(\frac{x_{c t}}{k_{c t}}\right)-\psi_{c}\left(\frac{x_{c t}}{k_{c t}}\right)\right]-\mu_{c t} \delta_{c}, \\
& -\dot{\mu}_{x t}+\mu_{x t} \rho=\lambda_{t} r_{x t}+\lambda_{t} p_{t}\left[\frac{x_{x t}}{k_{x t}} \psi_{x}^{\prime}\left(\frac{x_{x t}}{k_{x t}}\right)-\psi_{x}\left(\frac{x_{x t}}{k_{x t}}\right)\right]-\mu_{x t} \delta_{x}, \\
& \lim _{t \rightarrow \infty} \mu_{c t} k_{c t}=\lim _{t \rightarrow \infty} \mu_{x t} k_{x t}=0 .
\end{aligned}
$$

We now turn to the production side of the model economy. The representative firm of the consumption-producing sector solves:

$$
\max _{c_{t}, k_{c t}, l_{c t}} \pi_{c t} \equiv c_{t}-r_{c t} k_{c t}-w_{c t} l_{c t} \quad \text { s.t. } \quad c_{t}=k_{c t}^{a} l_{c t}^{1-a}, \quad c_{t}, l_{c t}, k_{c t} \geq 0
$$

where $a \in(0,1)$ is the constant capital share parameter. The first-order conditions are the 
production function and

$$
\begin{aligned}
r_{c t} & =a k_{c t}^{a-1} l_{c t}^{1-a}, \\
w_{c t} & =(1-a) k_{c t}^{a} l_{c t}^{-a} .
\end{aligned}
$$

For future reference, note that the production function and (6b) imply that

$$
\begin{aligned}
& l_{c t}=1-a, \\
& c_{t}=(1-a)^{1-a} k_{c t}^{a} .
\end{aligned}
$$

The representative firm of the capital-producing sector solves:

$$
\max _{x_{t} l_{x t}, k_{x t}} \pi_{x t} \equiv p_{t} x_{t}-r_{x t} k_{x t}-w_{x t} l_{x t} \quad \text { s.t. } \quad x_{t}=B_{t} k_{x t}^{b} l_{x t}^{1-b}, \quad x_{t}, k_{x t}, l_{x t} \geq 0
$$

where $b \in(0,1)$ denotes the constant capital share parameter and $B_{t} \geq 0$ denotes total factor productivity in the sector, which is given from the representative firm's perspective. The firstorder conditions are the production function and

$$
\begin{gathered}
r_{x t}=p_{t} b B_{t} k_{x t}^{b-1} l_{x t}^{1-b}, \\
w_{x t}=p_{t}(1-b) B_{t} k_{x t}^{b} l_{x t}^{-b} .
\end{gathered}
$$

$B_{t}$ is specified so that there are positive externalities at the level of the capital-producing sector. This is consistent with the empirical evidence in favor of positive externalities in the production of manufacturing durables [Basu and Fernald (1997)]. The externalities are modeled as is standard in the related literature by assuming that total factor productivity in the capital-producing sector depends on aggregate output there. Recalling that there is a measure one of firms in each 
sector, this gives:

$$
B_{t}=k_{x t}^{\theta b} l_{x t}^{\theta(1-b)}
$$

where $\theta \in\left[0, \frac{1-b}{b}\right)$. Substituting (10a) back into the production function, aggregate capital output becomes:

$$
x_{t}=k_{x t}^{\beta_{1}} l_{x t}^{\beta_{2}}
$$

where

$$
\beta_{1} \equiv(1+\theta) b, \quad \beta_{2} \equiv(1+\theta)(1-b) .
$$

Some features of this specification deserve further comment. First, the upper bound $\frac{1-b}{b}$ on $\theta$ is imposed to exclude the possibility of endogenous growth and to guarantee the stationarity of our model economy. For plausible parameter values it will not be binding. Second, (10a) implies that the externalities on capital and labor are the same. The reason for this assumption is that separate estimates for the strength of the resulting increasing returns do not exist. ${ }^{2}$ Third, as is standard, the externality is not taken into account by the individual firms in the capitalproducing sector, so a competitive equilibrium exists. Moreover, equilibrium profits are zero (and will be omitted from now on) and the capital and labor shares are the usual ones: $\frac{r_{x t} k_{x t}}{k_{t}}=b$ and $\frac{w_{x t} l_{x t}}{k_{t}}=1-b$. Of course, in a competitive equilibrium the $B_{t}$ on which the firms base their decisions must be equal to the $B_{t}$ that results from these decisions:

Definition 1 (Competitive equilibrium) A competitive equilibrium are prices $\left\{w_{c t}, w_{x t}, r_{c t}, r_{x t}\right.$, $\left.p_{t}\right\}_{t=0}^{\infty}$, allocations $\left\{c_{t}, l_{c t}, l_{x t}, x_{t}, x_{c t}, x_{x t}, k_{c t}, k_{x t}\right\}_{t=0}^{\infty}$, and total factor productivity in the capitalproducing sector $\left\{B_{t}\right\}_{t=0}^{\infty}$ such that: (i) $\left\{c_{t}, l_{c t}, l_{x t}, x_{t}, x_{c t}, x_{x t}, k_{c t}, k_{x t}\right\}_{t=0}^{\infty}$ solve the problem of the representative household; (ii) $\left\{c_{t}, l_{c t}, k_{c t}\right\}_{t=0}^{\infty}$ solve the problem of the representative firm of the consumption-producing sector, (5); (iii) $\left\{x_{t}, l_{x t}, k_{x t}\right\}_{t=0}^{\infty}$ solve the problem of the representative firm of the capital-producing sector, (8); (iv) $B_{t}$ is determined consistently, that is, (10a) holds.

\footnotetext{
${ }^{2}$ The results of Harrison and Weder (2001) suggest that imposing this constraint does not affect the stability properties of two-sector models in an important way.
} 


\section{Equilibrium Dynamics}

Combining the first-order conditions derived above, it can be shown that with (HP1) the equilibrium dynamics is characterized by the terminal conditions (3f) together with the following eight equations in the eight unknowns $x_{c t}, x_{x t}, k_{c t}, k_{x t}, \mu_{c t}, l_{x t}, p_{t}$, and $\lambda_{t}$ :

$$
\begin{aligned}
& k_{x t}^{\beta_{1}} l_{x t}^{\beta_{2}}=\left(k_{c t}+k_{x t}\right) \psi\left(\frac{x_{c t}+x_{x t}}{k_{c t}+k_{x t}}\right), \\
& \frac{\mu_{c t}}{\lambda_{t} p_{t}}=\psi^{\prime}\left(\frac{x_{c t}+x_{x t}}{k_{c t}+k_{x t}}\right), \\
& 1=\lambda_{t} p_{t}(1-b) k_{x t}^{\beta_{1}} l_{x t}^{\beta_{2}-1}, \\
& (1-a)^{1-a} k_{c t}^{a}=p_{t}(1-b) k_{x t}^{\beta_{1}} l_{x t}^{\beta_{2}-1}, \\
& \frac{a}{k_{c t}}-\mu_{c t} \delta_{c}=\frac{b}{1-b} \frac{l_{x t}}{k_{x t}}-\mu_{c t} \delta_{x}, \\
& \dot{\mu}_{c t}=\mu_{c t}\left[\rho+\delta_{c}+\frac{x_{c t}+x_{x t}}{k_{c t}+k_{x t}}-\frac{\psi\left(\frac{x_{c t}+x_{x t}}{k_{c t}+k_{x t}}\right)}{\psi^{\prime}\left(\frac{x_{c t}+x_{x t}}{k_{c t}+k_{x t}}\right)}\right]-\frac{a}{k_{c t}}, \\
& \dot{k}_{c t}=x_{c t}-\delta_{c} k_{c t}, \\
& \dot{k}_{x t}=x_{x t}-\delta_{x} k_{x t} .
\end{aligned}
$$

Equation (11a) specifies how the equilibrium supplies of the two new capital goods are related to the output of the capital-producing sector. It follows by substituting the first equation of (10b) into (2a). Equation (11b) restates equation (3c). It specifies how the equilibrium demands of the two new capital goods depend on the relative price of installed capital in terms of new capital, $\frac{\mu_{c t}}{\lambda_{t} p_{t}}$, which is called Tobin's $q$. Note that the presence of adjustment costs permits variation in Tobin's $q \cdot{ }^{3}$ Equation (11c) says that the marginal utility from leisure is to be equalized to the marginal utility from the increase in the capital-producing sector's output due to the last unit of labor. It follows by substituting (9b), (10a), and (11b) into (3a). Equation (11d) says that the

\footnotetext{
${ }^{3}$ When we speak of Tobin's $q$ here, we mean marginal $q$. In any case, there is no difference between marginal $q$ and average $q$ in our model because the capital adjustment costs used here are linear homogeneous in its arguments [Hayashi (1982)].
} 
marginal products of labor are to be equalized in equilibrium. It follows by substituting (6b) and (9b) into (3a). Equation (11e) says that the marginal products of installed capital net of depreciation are to be equalized in equilibrium. Note that with (HP1) this holds in equilibrium because the costs come from adjusting the total capital stock irrespective of how two sectors' capital stocks are adjusted. (11e) follows by substituting (6a), (7), the production function of (8), (9a), and (10a) into (3d). Equation (11f) describes the equilibrium law of motion of the shadow price of installed capital. It follows by substituting (3c), (6a), and (7) into (3e). Note that since with (HP1) the shadow prices of the two installed capital goods are equal, only one law of motion is required. The equations in $(11 \mathrm{~g})$ and $(12 \mathrm{~h})$ are the laws of motion from (2c) and $(2 \mathrm{~d})$ once more.

Combining the first-order conditions derived above, it can be shown that with (HP2) the equilibrium dynamics is characterized by the terminal conditions (4f) together with the following nine equations in the nine unknowns $x_{c t}, x_{x t}, k_{c t}, k_{x t}, \mu_{c t}, \mu_{x t}, l_{x t}, p_{t}$, and $\lambda_{t}$ :

$$
\begin{aligned}
& k_{x t}^{\beta_{1}} l_{x t}^{\beta_{2}}=k_{c t} \psi_{c}\left(\frac{x_{c t}}{k_{c t}}\right)+k_{x t} \psi_{x}\left(\frac{x_{x t}}{k_{x t}}\right), \\
& \frac{\mu_{c t}}{\lambda_{t} p_{t}}=\psi_{c}^{\prime}\left(\frac{x_{c t}}{k_{c t}}\right), \\
& \frac{\mu_{x t}}{\lambda_{t} p_{t}}=\psi_{x}^{\prime}\left(\frac{x_{x t}}{k_{x t}}\right), \\
& 1=\lambda_{t} p_{t}(1-b) k_{x t}^{\beta_{1}} l_{x t}^{\beta_{2}-1}, \\
& (1-a)^{1-a} k_{c t}^{a}=p_{t}(1-b) k_{x t}^{\beta_{1}} l_{x t}^{\beta_{2}-1}, \\
& \dot{\mu}_{c t}=\mu_{c t}\left[\rho+\delta_{c}+\frac{x_{c t}}{k_{c t}}-\frac{\psi_{c}\left(\frac{x_{c t}}{k_{c t}}\right)}{\psi_{c}^{\prime}\left(\frac{x_{c t}}{k_{c t}}\right)}\right]-\frac{a}{k_{c t}}, \\
& \dot{\mu}_{x t}=\mu_{x t}\left[\rho+\delta_{x}+\frac{x_{x t}}{k_{x t}}-\frac{\psi_{x}\left(\frac{x_{x t}}{k_{x t}}\right)}{\psi_{x}^{\prime}\left(\frac{x_{x t}}{k_{x t}}\right)}\right]-\frac{b}{1-b} \frac{l_{x t}}{k_{x t}}, \\
& \dot{k}_{c t}=x_{c t}-\delta_{c} k_{c t}, \\
& \dot{k}_{x t}=x_{x t}-\delta_{x} k_{x t} .
\end{aligned}
$$


Equation (12a) specifies how the equilibrium productions of the two new capital goods are related to the output of the capital-producing sector. It follows by substituting the (10b) into (2i). The equations in (12b) and (12c) restate equations (4c) and (4c). They specify how the equilibrium demands of the two new capital goods depend on the relative prices of installed capital in terms of new capital, $\frac{\mu_{c t}}{\lambda_{t} p_{t}}$ and $\frac{\mu_{x t}}{\lambda_{t} p_{t}}$. Equations (12d) and (12e) are equations (11c) and (11d) once more. Equations (12f) and (12g) describe the equilibrium laws of motion of the shadow prices of installed capital. Note that with (HP2) the marginal products of installed capital net of depreciation need no longer be equal because the costs of adjusting the two sectors' capital stocks can drive a wedge between them. (12f) and (12g) follow by substituting (4c) and (4c) into (4d) and (4e), respectively, and plugging (6a) and (7) into the results. The equations in $(12 \mathrm{~h})$ and $(12 \mathrm{i})$ are the laws of motion from $(2 \mathrm{c})$ and $(2 \mathrm{~d})$ once more.

In order to guarantee the existence of a steady state, we need to put more structure on $\psi$, $\psi_{c}$, and $\psi_{x}$. We adopt the standard assumption that the capital adjustment costs do not affect the steady state of the model economy. Denoting steady state variables by dropping the time index, this gives six restrictions:

$$
\begin{array}{ll}
\psi\left(\frac{x_{c}+x_{x}}{k_{c}+k_{x}}\right)=\frac{x_{c}+x_{x}}{k_{c}+k_{x}}, & \psi^{\prime}\left(\frac{x_{c}+x_{x}}{k_{c}+k_{x}}\right)=1, \\
\psi_{c}\left(\frac{x_{c}}{k_{c}}\right)=\frac{x_{c}}{k_{c}}, & \psi_{c}^{\prime}\left(\frac{x_{c}}{k_{c}}\right)=1, \\
\psi_{x}\left(\frac{x_{x}}{k_{x}}\right)=\frac{x_{x}}{k_{x}}, & \psi_{x}^{\prime}\left(\frac{x_{x}}{k_{x}}\right)=1 .
\end{array}
$$

Thus, we are left with the three second derivatives as free parameters, which will play a key role for the local stability properties of the steady state.

Proposition 1 (Steady state) Given (15), there is a unique steady state. The steady state is the same for (HP1) and (HP2). 
Proof. Given (15), the steady state versions of (11) and (12) both become:

$$
\begin{aligned}
& k_{x}^{\beta_{1}} l_{x}^{\beta_{2}}=x_{c}+x_{x}, \\
& 1=\frac{\mu_{c}}{\lambda p}=\frac{\mu_{x}}{\lambda p}, \\
& 1=\lambda p(1-b) k_{x}^{\beta_{1}} l_{x}^{\beta_{2}-1} \\
& (1-a)^{1-a} k_{c}^{a}=p(1-b) k_{t}^{\beta_{1}} l_{x}^{\beta_{2}-1}, \\
& \frac{a}{k_{c}}-\mu_{c} \delta_{c}=\frac{b}{1-b} \frac{l_{x}}{k_{x}}-\mu_{x} \delta_{x}, \\
& 0=\mu_{c}\left(\rho+\delta_{c}\right)-\frac{a}{k_{c}}, \\
& x_{c}=\delta_{c} k_{c}, \quad x_{x}=\delta_{x} k_{x} .
\end{aligned}
$$

Consolidating (16), we obtain the following three equations in the three unknowns $k_{c}, k_{x}$, and $l_{x}$ :

$$
\begin{aligned}
k_{x}^{\beta_{1}} l_{x}^{\beta_{2}} & =\delta_{c} k_{c}+\delta_{x} k_{x}, \\
\frac{\rho+\delta_{c}}{a(1-b)} & =\frac{k_{x}^{\beta_{1}} l_{x}^{\beta_{2}-1}}{k_{c}}, \\
\frac{\rho+\delta_{x}}{\rho+\delta_{c}} \frac{a}{k_{c}} & =\frac{b}{1-b} \frac{l_{x}}{k_{x}} .
\end{aligned}
$$

That these equations have a unique solution can be seen as follows. First, solve (17c) for $k_{c}$ and substitute the result into (17b). This gives $l_{x}$ as a function of $k_{x}$. Substitute this into (17a) to get $k_{c}$ as a linear function of $k_{x}$. Substituting this into (17c) gives $l_{x}$. Obtaining $k_{x}$ and $k_{c}$ is then straightforward. 


\section{Local Stability Properties}

We start the discussion of the local stability properties with the observation that the reducedform equilibrium dynamics with (HP1) and with (HP2) have different dimensions. With (HP1) the dynamics is two dimensional and it is composed of the aggregate capital stock as the state and of one control, which we choose to be $\mu_{c t}$. This is like in the model version without capital adjustment costs. The reason is that the capital adjustment costs in (HP1) accrue from changes in the total capital stock, $k_{c t}+k_{x t}$, so $\mu_{c t}=\mu_{x t}$; see (3b). As a result, it remains costless to change the allocation of a given total capital stock across the two sectors. With (HP2) the dynamics is four dimensional and it is composed of the two sectors' capital stocks $k_{c t}$ and $k_{x t}$ as the states and of two controls, which we choose to be $\mu_{c t}$ and $\mu_{x t}$. This is unlike the model version without capital adjustment costs. The reason is that the capital adjustment costs in (HP2) accrue from changes of each of the two sectors' capital stocks separately, so $\mu_{c t} \neq \mu_{x t}$; see (4b). As a result, it becomes costly to change the allocation of a given total capital stock across the two sectors and each sector's capital stock becomes a state and the corresponding shadow price a control.

The steady state is saddle-path stable if and only if the matrix of the linearization at the steady has as many stable roots (i.e. roots with negative real part) as states and as many unstable roots (i.e. roots with positive real part) as controls. If the steady state is saddle-path stable, then the equilibrium nearby is determinate, that is, given the initial capital stocks close to the steady state values there are unique initial shadow prices such that the economy converges to the steady state. The steady state is stable if and only if it has more stable roots than states. If the steady state is stable, then the equilibrium nearby is locally indeterminate, that is, given the initial capital stocks close to the steady state pair there exists a continuum of shadow prices such that the economy converges to the steady state. The steady state is unstable if and only if has more unstable roots than controls.

Since the reduced-form equilibrium dynamics with (HP1) is two dimensional, one could in principle compute the two eigenvalues and characterize the local stability properties analyti- 
cally in this first case. This would be very messy though. Since the dynamics with (HP2) is four dimensional, it becomes impossible in this second case to compute the four eigenvalues analytically and to obtain analytical results. We will choose a functional form for $\psi, \psi_{c}$, and $\psi_{x}$ and empirically plausible parameters values and we will then compute numerically the eigenvalues for both cases numerically. Specifically, we follow Boldrin et al. (2001) and set

$$
\begin{aligned}
\psi\left(\frac{x_{c t}+x_{x t}}{k_{c t}+k_{x t}}\right) & =\kappa_{1}+\frac{\kappa_{2}}{1+\varphi}\left[\frac{x_{c t}+x_{x t}}{k_{c t}+k_{x t}}\right]^{1+\varphi}, \\
\psi_{c}\left(\frac{x_{c t}}{k_{c t}}\right) & =\kappa_{c 1}+\frac{\kappa_{c 2}}{1+\varphi}\left[\frac{x_{c t}}{k_{c t}}\right]^{1+\varphi}, \\
\psi_{x}\left(\frac{x_{x t}}{k_{x t}}\right) & =\kappa_{x 1}+\frac{\kappa_{x 2}}{1+\varphi}\left[\frac{x_{x t}}{k_{x t}}\right]^{1+\varphi},
\end{aligned}
$$

where $\kappa_{1}, \kappa_{2}, \kappa_{c 1}, \kappa_{c 2}, \kappa_{x 1}, \kappa_{x 2}$, and $\varphi$ are constants. The six $\kappa$-constants are chosen so as to ensure that the six restrictions listed in (15) are satisfied (i.e. there is no effect of the capital adjustment costs in steady state). The parameter $\varphi$ remains free and it affects the curvature of the capital adjustment costs. In fact, the expressions in (11b)-(12c) show that $\varphi$ is the inverse of the elasticity of the relevant investment-to-installed-capital ratio with respect to Tobin's $q$.

The inverse of the elasticity of the investment-to-installed-capital ratio with respect to Tobin's $q$ and the degree of increasing returns in the capital-producing sector are the key parameters that determine the local stability properties of the steady state. We will therefore not choose a benchmark calibration for them but vary them widely. To get an idea about the intervals in which plausible parameter choices can lie, we briefly report the key empirical evidence. Eberly (1997) estimates $\varphi$ from a panel of OECD countries and reports point estimates in [0.51, 1.54], with the US having 0.82. If one computes the confidence intervals of the different estimates, then the lowest possible realization for the whole sample is 0.34 , which comes from the French data, and the lowest possible realization for the US is 0.74. Jermann (1998) calibrates $\varphi$ the US economy and finds a much larger value: $4.35 .{ }^{4}$ We remain agnostic and just conclude that

\footnotetext{
${ }^{4}$ The discrepancy can be understood as follows. Jermann calibrates his model such that asset pricing paradoxes
} 
Figure 1: Local stability with $a=0.41, b=0.34, \rho=0.01, \delta_{c}=0.018, \delta_{x}=0.020$.

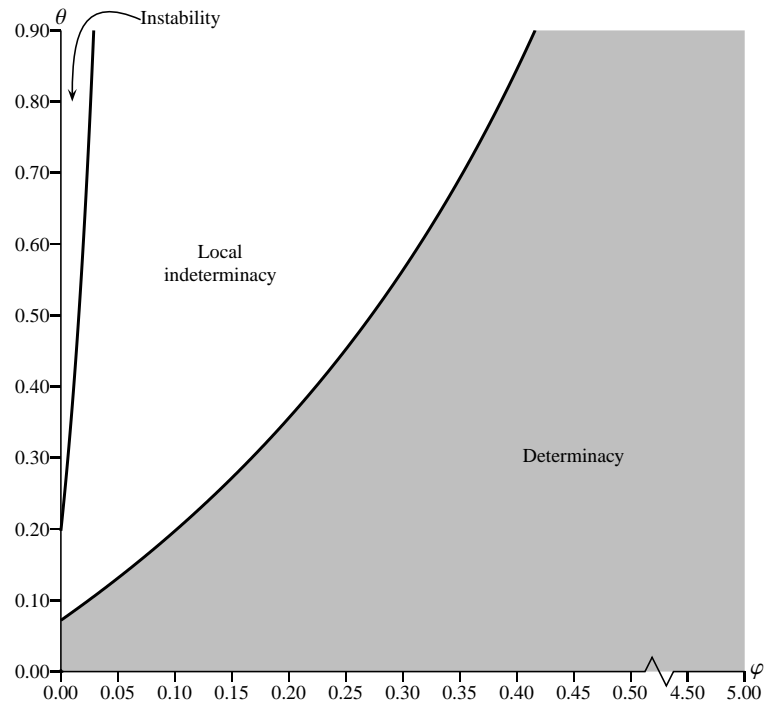

(a) costly adjustment of total capital

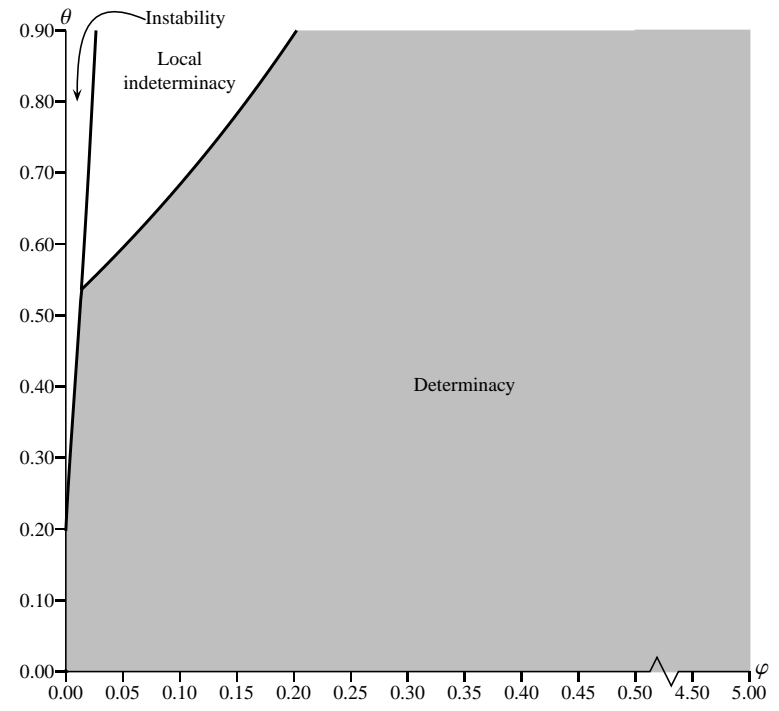

(b) costly adjustment of sectoral capital

values for $\varphi$ short of 0.34 are unreasonable. The evidence about $\theta$ is as follows. Hall's (1988) initially estimated $\theta \approx 0.5$. It turned out, however, that this estimate was upward biased. More recent empirical studies instead find estimates between constant returns and much milder increasing returns that at most might reach 0.3; see e.g. Bartelsman et al. (1994), Burnside et al. (1995), or Basu and Fernald (1997). It is generally agreed by now that values for $\theta$ in excess of 0.3 are unreasonable.

The remaining parameters to be chosen are $a, b, \rho, \delta_{c}$, and $\delta_{x}$. Some recent related studies set them as follows. Benhabib and Farmer (1996) choose $a=b=0.3, \rho=0.0125$, and $\delta_{c}=\delta_{x}=0.026$. Huffman and Wynne (1999) choose $a=0.41, b=0.34, \rho=0.01, \delta_{c}=0.018$, and $\delta_{x}=0.020$. Boldrin et al. (2001) choose $a=b=0.36, \rho=0.00001, \delta_{c}=\delta_{x}=0.021$. Since the parameter choices of Huffman and Wynne (1999) come from a serious calibration of a model that is very close to the one employed here, we will use their values. However, we will can be accounted for. High inverse elasticities are helpful to this end because they allow for persistent deviations of $\mathrm{q}$ from its steady state value. 
also conduct extensive sensitivity checks, which incorporate the other possibilities too, except for the rather awkward choice of $\rho=0.00001$.

The local stability properties for our benchmark calibration are summarized by Figure 1. In particular, part (a) shows the case of adjustment costs on total capital and part (b) shows the case of adjustment costs on sectoral capital. The main result of this paper is that, in both cases, determinacy of the steady state occurs for $\varphi \geq 0.34$ and $\theta \leq 0.3$, which, as we argued above, are necessary conditions for reasonable parameter values. This result turns out to be very robust to changes in the other parameter values, which can be established as follows: Fix $\varphi$ and $\theta$ at the two values that might still be defendable while local indeterminacy results most easily, $\varphi=0.34$ and $\theta=0.3$, thereby "loading the gun in favor of" local indeterminacy; then vary the other parameters: $\rho, \delta_{c}, \delta_{x}$ each in $[0.005,0.03]$ with step size $0.001, a$ and $b$ each in $[0.25,045]$ with step size $0.01 .^{5}$ The result is that there is no parameter combination on these grids for which the steady state is locally indeterminate; instead it is determinate everywhere.

Two interesting aspects of the above figures deserve further comment: The local indeterminacy range is significantly larger with costly adjustment of total capital whereas the determinacy parameter range is significantly larger with costly adjustment of sectoral capital. One implication of this fact is observed as the adjustment costs parameter $\varphi$ converges to 0 . For the first form of adjustment costs the local stability properties change from determinacy to local indeterminacy at $\theta=0.072$ and from local indeterminacy to instability at $\theta=0.198$. These threshold values are exactly the same as without capital adjustment costs [Herrendorf and Valentinyi (2002)], so the local stability properties change continuously as $\varphi$ goes to zero. In contrast, for the second form of adjustment costs the local stability properties do not change continuously; instead as $\varphi$ goes to zero the first threshold disappears and only the second one survives. ${ }^{6}$

The differences between the two forms of adjustment costs are related to the change of di-

\footnotetext{
${ }^{5}$ Note that $a$ does not matter at all for the local stability properties.

${ }^{6}$ Note that in the second case we could not formally take the limit in the numerical computations. The smallest $\varphi$ we considered was 1.000000001 .
} 
mension of the reduced-form dynamics from four to two, which has important implications for Tobin's $q$. Specifically, if adjusting total capital is costly, then the equilibrium relative prices of both new capital goods are equal and there is only one Tobin's $q$. This one relative price affects the consumption/savings decision of the representative household but has no instantaneous effect on the two sectoral investments. So, in this case, capital adjustment costs only affect the local stability because they partly offset the increasing returns. In contrast, if adjusting each sector's capital is costly, then the equilibrium relative prices of each sector's new capital goods are different and there two Tobin's $q$ 's. These two relative prices do not only affect the consumption/savings decision but also the sectoral investments. For example, if one $q$ rises relative to the other one, then instantaneously more new capital goods are channeled to the sector where $q$ has risen. So, in this case, the capital adjustment costs do not only offset partly the increasing returns but also determine the allocation of new capital goods to the two sectors, thus eliminating one degree of freedom. In a follow-up paper, Herrendorf and Valentinyi (2002), we study this second effect in more detail for intratemporal capital adjustment costs. ${ }^{7}$

\section{Conclusion}

In this paper we have explored how plausible the idea is that business cycle fluctuations can be driven by self-fulfilling changes in individual beliefs. It would be plausible if the steady state were locally indeterminate for empirically reasonable choices of the parameter values. We have explored this possibility in the standard two-sector version with mild sector-specific externalities, which has been the focus of much of the recent research on self-fulfilling business cycles. We have found that the introduction of standard intertemporal capital adjustment costs excludes self-fulfilling business cycles for all empirically reasonable choices of the parameter

\footnotetext{
${ }^{7}$ The difference between intertemporal and intratemporal capital adjustment costs is as follows. Intratemporal capital adjustment costs accrue when the allocation of capital across sectors is changed but not when the total capital stock is changed as long as that allocation remains the same. Intertemporal capital adjustment costs accrue in both cases.
} 
values. This finding turns out to be independent of whether these adjustment costs arise from changes of the total capital stock or from changes of each sector's capital stock.

The results of this paper imply that the occurrence of local indeterminacy in the two-sector real business cycle model with sector-specific externalities is not robust. This suggests that other versions of the neoclassical growth model are required to demonstrate the plausibility of selffulfilling business cycles. One possibility is opened by the recent work of Wen (1998a), who shows that local indeterminacy can occur in the one-sector version of the model for reasonable parameter values when capital utilization is variable. Guo and Harrison (2001) confirm that also in the standard two-sector model variable capital utilization decreases the degree of increasing returns that yield local indeterminacy. Exploring the robustness of this new channel to capital adjustment costs is an interesting topic, which we leave for future research.

\section{References}

Bartelsman, Eric, Ricardo Caballero, and Richard K. Lyons, "Consumer and Supplier Driven Externalities," American Economic Review, 1994, 84, 1075-1084.

Basu, Susanto and John G. Fernald, "Returns to Scale in U.S. Production: Estimates and Implications," Journal of Political Economy, 1997, 105, 249-283.

Benhabib, Jess and Roger E. A. Farmer, "Indeterminacy and Increasing Returns," Journal of Economic Theory, 1994, 63, 19-41.

— and — , "Indeterminacy and Sector-Specific Externalities," Journal of Monetary Economics, 1996, 37, 421-443.

Boldrin, Michele and Aldo Rustichini, "Growth and Indeterminacy in Dynamic Models with Externalities," Econometrica, 1994, 62, 323-342. 
—, Lawrence J. Christiano, and Jonas D.M. Fisher, "Habit Persistence, Asset Returns and the Business Cycle," American Economic Review, 2001, 91, 149-166.

Burnside, Craig, Martin Eichenbaum, and Sergio Rebelo, "Capital Utilization and Returns to Scale," in Ben S. Bernanke and Julio J. Rotemberg, eds., NBER Macroeconomics Annual 1995, Cambridge, MA: MIT Press, 1995.

Christiano, Lawrence J., "A Discrete-Time Version of Benhabib-Farmer II," Manuscript, Northwestern University, Evanston, IL 1995.

Eberly, Janice J., "International Evidence on Investment and Fundamentals," European Economic Review, 1997, 41, 1055-1078.

Guo, Jang-Ting and Kevin J. Lansing, "Fiscal Policy, Increasing Returns and Endogenous Fluctuations," forthcoming: Macroeconomic Dynamics, 2002.

_ and Sharon G. Harrison, "Indeterminacy with Capital Utilization and Sector-Specific Externalities,” Economics Letters, 2001, 72, 355-360.

Hall, Robert E., "Relation Between Price and Marginal Cost in U.S. Industry," Journal of Political Economy, 1988, 96, 921-947.

Hammermesh, Daniel S. and Gerard Pfann, “Adjustment Costs and Factor Demand,” Journal of Economic Literature, 1996, 39, 1264-1292.

Hansen, Gary D., "Indivisible Labor and the Business Cycle," Journal of Monetary Economics, 1985, 16, 309-328.

Harrison, Sharon G. and Mark Weder, "Tracing Externalities as Sources of Indeterminacy," Journal of Economic Dynamics and Control, 2001, 26, 851-867.

Hayashi, Fumio, “Tobin's Marginal q and Average q: A Neoclassical Interpretation,” Econometrica, 1982, 50, 213-224. 
Herrendorf, Berthold and Ákos Valentinyi, "On the Stability of the Two-sector Neoclassical Growth Model with Externalities,” Discussion Paper 3435, CEPR 2002.

Hintermaier, Thomas, "Lower Bounds on Externalities in Sunspot Models," forthcoming: Journal of Economic Theory, 2002.

Huffman, Gregory W. and Mark A. Wynne, "The Role of Intratemporal Adjustment Costs in a Multisector Economy," Journal of Monetary Economics, 1999, 43, 317-350.

Jermann, Urban J., “Asset Pricing in Production Economies," Journal of Monetary Economics, 1998, 41, 257-275.

Kim, Jinill, "Indeterminacy and Investment Adjustment Cost: An Analytical Result," forthcoming: Macroeconomic Dynamics, 2003.

Kydland, Finn E. and Edward C. Prescott, "Time to Build and Aggregate Fluctuations," Econometrica, 1982, 50, 1345-1370.

Lucas, Robert E. Jr. and Edward C. Prescott, "Investment under Uncertainty," Econometrica, 1971, 39, 659-681.

Perli, Roberto, "Indeterminacy, Home Production, and the Business Cycle: A Calibrated Analysis," Journal of Monetary Economics, 1998, 41, 105-125.

Ramey, Valerie A. and Matthew D. Shapiro, "Displaced Capital: A Study of Aerospace Plant Closings," Journal of Political Economy, 2001, 109, 958-992.

Schmitt-Grohé, Stephanie, "Endogenous Business Cycles and the Dynamics of Output, Hours, and Consumption," American Economic Review, 2000, 90, 1136-1158.

Weder, Mark, "Fickle Consumers, Durable Goods, and Business Cycles," Journal of Economic Theory, 1998, 81, 37-57. 
Wen, Yi, "Capacity Utilization under Increasing Returns to Scale," Journal of Economic Theory, 1998, 81, 7-36.

—_, "Indeterminacy, Dynamic Adjustment Costs, and Cycles," Economics Letters, 1998, 59, 213-216. 